\title{
[Eco]systems of resilience practices: a reframing from the Experience of Italian Resilience Practices Observatory
}

\author{
Angela Colucci $^{1, *}$ and Giulia Pesaro ${ }^{2}$ \\ ${ }^{1}$ Politecnico di Milano, Milan, Italy / Piazza Leonardo da Vinci 26, 20133 Milano, Tel. \\ $+393381057288$ \\ ${ }^{2}$ Politecnico di Milano, Milan, Italy / Piazza Leonardo da Vinci 26, 20133 Milano \\ E-Mails: angela.colucci@polimi.it ; giulia.pesaro@polimi.it
}

\begin{abstract}
Over time, an increasing number of institutions are investing in resilience of communities and territories, supporting local based practices and actions. Launched in April 2015 and promoted by a partnerships between Academic institutions (Politecnico di Milano) as coordinator) and the REsilienceLAB association and funded by Fondazione Cariplo the Resilience Practices Observatory (RPO) takes as its overall strategic objective the enhancement of territorial resilience through the strengthening of resilience practices. Inside the RPO activities, a specific working space has been devoted to three crosscutting issues (governance, knowledge co-production and economy) that are crucial in enhancing the feasibility and the stabilization of resilience practices and in contributing to social and territorial resilience in the long-run. The essay first offers a brief introduction to the RPO working experience which, in these two years, based on a strong interdisciplinary and collaborative approach, proved to be successful and able to highlight strengths and weaknesses of the resilience implementation from the operational perspective and to envisage innovative tools to be applied in a new generation of multipurpose projects. Then, a specific focus on the governance issue $t$ will be introduced, highlighting main conceptual reframing and toolboxes developed. In the final part of the essay, reframing frameworks, methodological and operational factors will hence be discussed (in particular, the concept of ecosystems of resilience practices), in order to highlight emerging trajectories for the improvement of resilience practices and policies to guarantee systemic and synergic benefits in resilience capabilities enhancement of complex territorial systems.
\end{abstract}

Keywords: Resilience practices; stabilization; governance; economic approach; knowledge co-production 


\section{Introduction}

In recent years, there has been a remarkable expansion in the use of resilience concept and a parallel wider diffusion of resilience practices, making territorial and societal quality a central element in urban and territorial innovative actions and investments. Resilience has increasingly become a crucial quality of territorial and social systems and of the communities of territorial actors, underlining the meaning of active adaptive behaviour which is entailed in the concept (Duit et al. 2010).

The diffusion of the resilience practices seems strongly correlated to the capability to make communities and territorial stakeholders understand, better then when addressing sustainability, the positive impacts coming from a change not only driven by administrative bodies or institutions but in a bottom-up perspective (Colucci, 2016). The same looking at the effectiveness of projects based on local, inclusive and small scale as the reference intervention dimensions (Sellberg et al. 2018). The strength of resilience is therefore in the growing multiplicity of concrete experiences and operational applications designed and implemented at the local territorial level (Colucci 2018). Resilience practices could be considered as transition initiatives or a process driven (and acted) by multiple (local) actors and in which activities aim to improve services, approaches, routines, practices and/or infrastructures existing within the city region boundaries (Frantzeskaki and Kabisch 2016). A commonality emerged from the literature debate is that environmental issues are explicitly integrated in the goals in a large rage of transition initiatives in terms of Climate change mitigation and adaptation strategies or in terms of resilience capacities strengthening: it was assumed also a criteria in selecting the transition initiatives practices (Colucci 2018).

Due to the large diffusion of resilience practices also supported by international and local Agencies and private foundations (e.g. 100 resilient cities campaign by Rockefeller Foundation or, locally the Resilient Communities launched by Cariplo Foundation) it is now important to better understand the results (impacts) deriving from these complex geographies of transition/resilience practices and to highlight strategies and instruments to improve the quality of practices, stabilize the results and towards renovated governance process able to enhance the system perspective in public and private programs.

The essay first introduces the meaning and goals of the RPO and offers a perspective on the functioning elements, activities and results, a brief overview follows on the database of practices built up during the RPO activities. As keys for the success of the resilience practices, three main issues emerged from the RPO activities: the governance of the design and implementation processes; the emerging importance of the economic thinking and action models to enhance the feasibility of the practices; the capacity building as a crucial element to enhance the concept of resilience and the related implementation paths from an operational perspective. This paper focuses on the governance aspects.

\section{The Italian Resilience Practices Observatory (RPO)}

As already mentioned above, a variety of different definitions and meanings accompany the term resilience when applied to communities and territorial areas. The maintaining of the more large and inclusive possible understanding of the concept has been one of the bases of the RPO functioning and 
of the practices collection. The focus still remains on the idea of resilience as an adaptation dynamics, as in Holling, for which resilience assumes a dynamic and evolutionary vision of possible response mechanisms in complex territorial systems (Holling 1973; Gunderson, L., et al. 2002). Thus, the strengthening of the resilience properties of complex systems like territorial areas carries the same systems to develop the capability to activate responses, adapt and change facing exogenous or endogenous disturbances. They reconfigure towards new equilibrium conditions, in a learning and development process able to produce new capacities to ride future changes and not to suffer too much their impacts.

It is in such a scenario that Fondazione Cariplo, an important Bank Foundation which finances many environmental and social initiatives, launched a call for funding called Resilient Communities. This made local communities, in the territorial area concerned by the funding activity of Fondazione Cariplo (the whole Lombardy region and a small portion of Piedmont), to propose, imagine and build up resilience practices.

Fondazione Cariplo received a great number of project proposals for implementing resilience practices at the community and territorial levels. In the considered years (2014 to 2016) the foundation funded 41 projects. It was clear that such an amount of proposals coming from the territories, looking both at the funded and non-funded ones, had to be regarded as a precious knowledge resource. On such bases, it has been proposed to build an Observatory with the goal of producing new knowledge founded on the collection, analysis and interpretation of the activities, projects and actions aimed at strengthening resilience of territories and communities in a long-term perspective. A place and a tool based on a clear interdisciplinary approach and intended to become a discussion arena and a toolbox itself. The Resilience Practices Observatory (RPO) officially started in April 2015 (Dezio et al. 2016) and it is a project coordinated by Department of Architecture and Urban Studies (DASTU) of the Politecnico di Milano, the association REsilienceLAB, Department of Science, Planning and Territorial Policies (DIST) of the Politecnico di Torino, the University of Molise and the Fondazione Lombardia per l'Ambienteand supported by Fondazione Cariplo.

The Observatory takes as its overall strategic objective the capacity building of territorial subjects to enhance resilience. This considering all territorial entities, institutions and communities involved in a long-term transition project, towards a stronger, aware and adaptive society, and the subjects themselves, which animate the RPO. This is why the RPO project design has been based on four main axes.

1. Mapping resilience initiatives at national level. Here the concept of "mapping" refers to the understanding of characteristics that differentiate initiatives and to the understanding of the territorial areas mainly involved in the resilience practices. This proved to be an important step towards the better understanding of the potentials of the multidimensional nature of the resilience concept "in action", when applied to urban and territorial practices.

2. Develop a set of tools and design criteria to support the dissemination of resilience practices. The goal is the building and offer of new tool sets and project design criteria to support the expansion and reinforcement of resilience practices and the building of solutions.

3. Produce developments in the cultural and methodological paths focusing on capacity building and innovation in knowledge approaches. The strategy relies on promoting scientific advancement about resilience and transition themes, based on applied research to territory and community. This to produce advances in scientific research in terms of conceptual and methodological innovation. 
4. Promoting the involvement of a huge actors' network. The definition of conceptual tools, both interpretative and for planning, aims at involve, in a process of mutual magnetization, the promoters and the community through the implementation of innovative and shared routes. This approach is based on a multi-sector and interdisciplinary perspective.

Figure 1. (a) Resilience practices observatory: a synthetic timeline and the main four axes
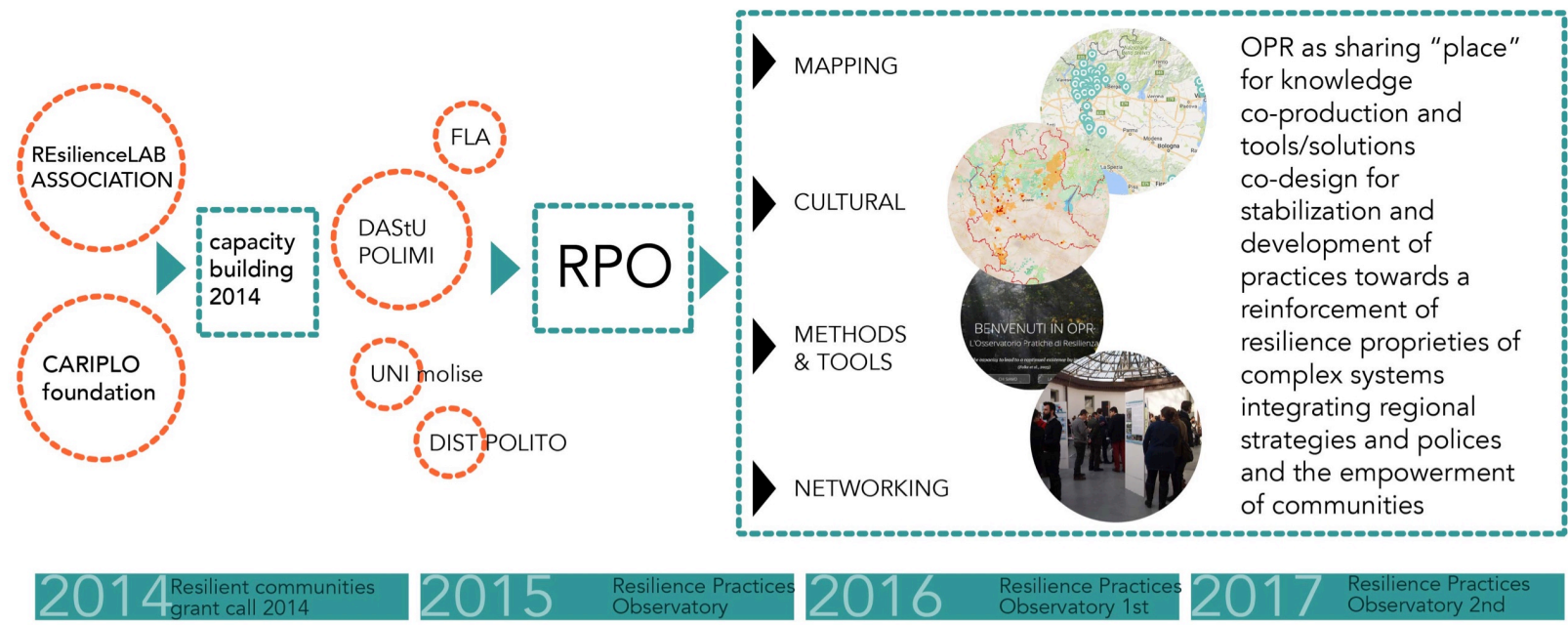

Source: Colucci 2018, p.177

The discourses on resilience concept and approaches, called the cultural path, have continually accompanied in a transversal and multi-sectorial way all the other activities of the Observatory. A work on the resilience concept reframing was than developed, in order to enhance the interdisciplinary approach and obtain a kind of "integrated and shared vocabulary" by which to better discuss and exchange with the Observatory stakeholders. During such activity, called the reframing phase, internal debate and workshops were organized, in order to explore all the opportunities and concepts deriving from engineering, ecosystem sciences, informatics (cybernetics) and psychological disciplinary approaches. A parallel activity was the collection and comparison between existing and consolidated practices (related to main approaches to resilience like risks, climate change, adaptation, transition) and the connection between theoretical models and the panorama of practices.

. Finally, one of the characteristics of the activities and of the actions oriented to resilience is that they presuppose networks of multiple subjects that support, participate, observe and implement the practices. The possible construction of an inclusive and stable network, which takes together academia, research, professionals, communities, local authorities and private and public institutions and bodies, proved to be an important and strategic transition and an essential element in approaching the reading and interpretation of resilience practices.

\section{The RPO practices database}

In the period since 2015 to the 2017 RPO engaged 103 resilience practices (the outcomes here presented are based on the database finalized on January 2017). Actually the RPO increased both the networking and the database (including more than 150 practices) thanks to the activities developed during the 2018 . 
The 103 practices engaged in the period 2015-2017 could be articulated in:

- 41 practices connected to the Cariplo foundation call on "resilient communities" (grant call targeted to NGO bodies that financed 41 project in four annual edition from 2014 to 2016) mostly located in Lombardy;

- 50 practices engaged during the RPO networking activities (Resilience Practices Forum);

- 16 applied researches (in which research and academic bodies play a coordination role).

The RPO organized two editions of the Forum of Resilience Practices (RPF) and several activities of knowledge exchange and knowledge co-production. In particular, the Resilience Practice Forums were launched as innovative instruments in order to engage and activate interdisciplinary and multiactors dialogues. During the two editions of the RPF $\left(29^{\text {th }}\right.$ January $2016 ; 24^{\text {th }}$ February 2017$)$ were involved 86 practices or initiatives activated by NGOs or local institutions and 16 researches applied to local contexts coordinated by universities or research centers directly involving the local communities

The RPF has then been configured as a path that connects different worlds: the first one is the world of the practices, or of the actors that implement the practices, and of the actors' promoters, which are public and private bodies that support and promote the initiatives and the resilience processes. The second one is the world of research and innovation, represented by universities, practitioners, international networks and national research centers.

Based on the practices engaged the main issues (or thematic levers) are:

- urban and territorial regeneration and local development (33\% of Practices). A large range of practices focuses on strategic vision for the re-development of depressed areas (internal areas but also peripheries and peri-urban areas in metropolitan contexts);

- food chains and natural resources cycles including biodiversity and natural habitats improvement (43\% of Practices). In most of the mapped practices, the food topic is strictly connected to the natural and ecosystem preservation issues (ecosystem services, natural areas improvement, agroecology...);

- climate change mitigation and adaptation and territorial risks (24\% of Practices). Only a few practices focus on Climate Change Adaptation as primary lever for practices promotion and those using this reading key refer to regional or territorial context and are usually connected to other existing process already activated (Mayor adapt, energy polices...). Some practices on sustainable river basin management (characterized by large partnership including institutions and national associations) include polices and measure for the risk prevention. Few of these focus on communities' risk preparedness and prevention in terms of self-help preparation and of intervention for the reduction of building vulnerability.

The database (2017, based on 103 practices) was analyzed in relation to the following categories: actors and policies: project leader, typology of practice; governance and territorial scale and impact, exploration aspects: criticalities addressed by the practice, characterizing topics, tools, territorial context

The main phenomena explored are below summarized (the percentages are based on 103 practices and the results below summarized were presented during the RPO congress on January 2018):

- The main actors of the interventions are associations (42,7\%), followed by public institutions (24\%) and other subjects from the research and no profit world. This is due to the nature itself of the funding systems as resilience is strictly connected to the wellbeing of 
local communities and is many times based on previous experiences in voluntary activities. The governance is mainly based on institutional driven processes (68\%);

- As mentioned above, the practices are mainly based on processes or on a mix of processes and specific local actions, which have to be developed in the territories and among the communities target of the practices. This was expected, as the attention is focused on concrete operational practices;

- About territorial scales of implementation and expected impacts, local and municipal implementation (29,9\% and 28,8\%) are accompanied by huger territorial and over local expected impacts $(32 \%$ and $22,7 \%)$. Only a few practices are conceived to remain in their small territorial frameworks, without an external dialogue;

- Up to now, the most involved sector is the environmental one $(49,3 \%)$, looking at biodiversity loss (25\%), hydrogeological risks (13,5\%) and environmental pressures $(10,8 \%)$. Territorial and soil depletion are the second action sectors, looking at abandonment $(20,9 \%)$ and urban decay $(11,5 \%)$. Even if in the last 10 years the crisis has hardly hit territories and communities, the database registers only a $4,7 \%$ of practices directly regarding economies and production and consumption models.

- The tools the practices count on for the implementation of the action programs are mainly capacity building $(35,9 \%)$ and the production of framework knowledge $(19,2 \%)$. These results make it clearer the needs communities and territories have in terms of enhancement of the local action strategies and capabilities to face problems and impacts coming not only from shocks and risks themselves but also from the changes of the socio-economic models and development paths.

About the feasibility of the projects or practices and the weaknesses and/or barriers to be overcome, the RPF have been important occasions to have a confrontation with the practices designers and stakeholders. The main weaknesses underlined by the practice designers and by the implementing communities can be summarized as follows:

- institutional barriers and administrative/bureaucratic weaknesses producing timing problems and obstacles in decision-making and activities needed to make the practices be implemented

- Lack of financial means or of stability and continuity of the funding;

- Scarce confidence in the feasibility and effectiveness of public-private cooperation needed to better face territorial criticisms;

- Weaknesses in the capabilities in "building" governance processes (in particular in relation to "people" involvement and engagement") but also difficulties in the building of local and over local networks (difficult relationships with already existing practices and processes).

\section{Up-scaling issues for enhancing urban resilience practices: focus on governance}

From the diversified activities related to the RPF meetings and discussions, three main issues emerged as fundamentals to guarantee the feasibility and the success of the implementation of practices. This also looking at a more general "growth and improvement" of the "cultural" conditions needed to stabilize and diffuse strategies towards a reinforcement of the resilience proprieties of complex systems, integrating regional strategies and polices and the empowerment of communities. 
The term governance refers to all differentiated mechanisms (self-regulation or informal rules of civil society; co-regulation of public and private actors and regulation through institutional government) through which individuals and institutions, public and private actors collaborate in managing common interest and social affairs (Dingwerth \& Pattberg 2006; Borraz \& Le Galès 2010).

A large range of researches and theoretical positions highlight the relevance and the urgency of a renovation of governance of urban transformation processes in order to cope with the complexity of environmental, social, economic and organizational phenomena characterizing the actual historical moment. The renovation of the governance process has to embrace cross system interactions and multi-scales phenomena and dynamics (temporal/spatial) of social-ecological systems (Ostrom, 1990, 2005). UN agencies launched campaigns promoting the implementation of "good urban governance" principles (for instance the UN-HABITAT programs and the UNISDR campaign on Making Resilient Cities); at the same time, Interregional polices of EU focus on the renovation of governance approaches. Shared issue is the development of renovated governance models able to integrate emerging phenomena (bottom-up and local innovation initiatives) and environmental, social and economic polices in the process of urban, metropolitan and regional systems transformation.

From the "resilience practices" dialogues activated by RPO emerge the lack of intentional "design" of governance process and the need of a capacity building and awareness on this aspect to reach a stabilisation (and improve the benefits to local/global systems) of resilience practices. These also imply an important confrontation about the renovation of the tool boxes, according to the innovative environment which should/could characterize the resilience practices: innovation in knowledge (co)production, in decision making process, in design and solutions identification (from "physical" and technical solutions to more complex and integrated strategies), implementation and management of initiatives (engagement and empowerment of all actors).

In relation to the characterization of governance models emerged from the practices involved in the RPO activities and database, it is possible to underline some general models, also recognisable in the international panorama of resilience practices and programs:

- an institutional leadership characterizes the climate change adaptation and prevention risk programs and plans: adaptation plans are usually promoted by metropolitan or city government. The whole of the processes promoted in the practices are voluntary, strategic and mainly characterized by a large range of participatory and inclusive paths, in order to involve and engage various stakeholders and include existing initiatives;

- bottom-up processes characterize transition initiatives that are activated, promoted and implemented through the mobilization and actions of citizens. A key factor for the success of the projects, in terms of consolidation and continuity of initiatives, is related to the ability to set up a strong and rich partnership around the initiative (with presence of associations, NGOs, private sector and public/institutions).

The RPF and RPO activities revealed a panorama showing the diffusion of new models of governance not included in the consolidated framework of regional and planning governance instruments. Inspiring concepts and proposals were developed in relation to metropolitan and urban regeneration processes, integrating environmental and ecosystem issues with social and economic innovation not only in terms of crosscutting and integrated solutions but also in terms of new models of governance. These dynamics clearly recall the concept of adaptive governance (Olsson et al., 2006) and reflexive governance (Voss et al., 2006) and can be seen as examples of innovative approaches to 
governance, where a mix of different tools can be found for the stakeholders engagement and empowerment.

The relevance of investigating (with renovated lens) the typical dichotomy of categories labelled as top-down and bottom-up emerges from the RPF practices panorama. Some "labelled" top down practices related to climate change adaptation and/or risk prevention are characterized by a complex governance process able to engage in the decision making process a large range of stakeholders (still remains the fact that governance processes are not homogeneous observing the panorama of climate change adaptation programs). At the same time investigating the quality of the governance process of initiatives promoted by local committees and associations (citizens, associations...) could be useful in order to better understand and evaluate the level of efficacy and inclusivity of bottom-up processes.

During the RP Forum, the engagement of citizen, communities and other territorial actors emerged as one of the most critical barrier for the implementation of the bottom-up practices panorama. The main interesting critical aspects could be highlighted as follows:

- lack of awareness in the definition (or design) of the actors "map" for the governance process: a clear stakeholders identification is a crucial aspect in order to reach the quality of governance;

- lack of an explicit involvement of stakeholders that could be able to support the resilience practices: private or public bodies able to support the implementation (economic grant/fund) and public and private actors working on the innovation like universities, research centres and consulting companies;

- lack of virtuous contaminations and alliances between sectors and actors. Difficulties in integrating different initiatives, polices and projects related to different sectors or spheres characterize (in different ways) almost all resilience practices. Processes promoted by public/institutional, private and civil society and or addressed to different sectors often are not converging.

\section{Eco-system of resilience practices: concluding remarks and perspectives}

The experiences of the RPO and of the RPF made emerge a great richness and variety of implementation sectors and thematic issues and projects designers able to imagine new and creative solutions. There is also an increasing number of institutional subjects able to activate the resilience practices by funding programs or other supporting activities addressed to the communities.

The results of the RPO work have enlightened some important issues as potential keys for the development of new methodologies and tools able to complement what has been done till today in the "resilience ordinary path" and to implement interdisciplinary and synergic transformative actions.

First, the principles those have to characterise the governance of a resilience process in order to support the development of participative processes of knowledge co-production and cultural evolution. These to better integrate resilience concepts and principles in the governance process of transformation of a complex system as a whole, following a holist approach. Second, the growing role of an economic approach able to sustain and accompany the project activities not only in a more integrated way but also in a more stable, continuous and coherent perspective, both referring to practices and projects and to public and institutional action. Consequently, a systemic approach able to favour integrated and innovative solutions could be or should be more encouraged, where solutions try to overcome conflicts and contradictions among different decision-making factors, gaining, at the same time, economic 
effectiveness and efficiency (Pesaro 2015). The goal is therefore to envisage solutions and tools by which the system could increase the global effectiveness and efficacy of non-ordinary and ordinary interventions and of the related investments. Moreover, synergies might be achieved by using a mix of different tools, assigning more importance and value to the whole of the territorial - economic resources of the systems. Finally, the renovated urgency to develop and promote innovations in knowledge building processes, capacity building and learning, all to be regarded as crucial key-tools and strategic factors in supporting resilience practices and, in general, the improvement of the resilience of complex systems.

\section{Eco-systems of resilience practices}

New adaptive urban governance frameworks are needed to build-up collaborative environments: this implies a radical shift from current governance models, generally based on linear (and consequential) process starting from goals definition, measures and polices prioritization to implementation phase (providing the achievement of targeted goals in a defined period of time), towards adaptive governance models capable to engage different stakeholders, emphasizing their role in defining multiple visions structured according to alternative scenarios in order to reach a shared and constantly updated set of goals (Geels 2002, Rotmans et al. 2001, Loorbach. 2010).

An adaptive urban governance framework should hence allow a multi-stakeholders process capable to firstly outline the long-term scenario (strategic vision). The concept of 'strategic long-term scenario' (developed by transition management theories) has similarities with the concept of 'threshold / boundaries' of socio-ecosystems proposed by resilience-think approaches and theories. The strategic scenario outlining coincides with the definition of 'preferred regime' threshold for urban complex system adaptation and evolution dynamics. This strategic vision should leave 'space' and opportunities for multiple possible trajectories of urban system dynamics of evolution that are necessary in order to cope (adapting consequently policies and actions) with uncertainty and constantly changing environmental, social, economic conditions but also to embrace innovative (un-expected) trajectories arising from grassroots initiatives and practices.

The networking of transition initiatives is emerging as a promising organizational structure that, if effectively integrated in the adaptive urban governance framework, could allow linking the different 'niches of innovation' and the more structured and consolidated organizational structures and stakeholders (e.g. institutional, civil society, private actors, universities), and it could become an innovative space of dialogue among different stakeholders (Colucci 2018).

By including the network of transition initiatives in the adaptive urban governance framework, it could be possible to promote and support the stabilisation, up-scaling, germination and improvement of community-led and transitions initiatives, improving the 'creative diversity' and redundancy proprieties of urban systems and sustaining a large catchment of innovation sources for adaptation.

Another element is the growing role of an economic approach able to sustain and accompany the project activities not only in a more integrated way but also in a more stable, continuous and coherent perspective, both referring to practices and projects and to public and institutional action (Pesaro 2015). This could become a system level goal of action, a general macro level reference for the medium and long term in a development perspective. A systemic goal which, by identifying some possible direct results, can help give greater coherence and to address the set of sectoral interventions in the territory, both small and great they might be in terms of investments, involved subjects, operational objectives and expected benefits. What is important is not the size but the internal 
consistency, necessary and central to converge on and help achieve common goals through a sequence of short-term activities, provided that they are more consistent and repeatable over time. The increasingly important contribution of the tools and of the methodologies characterizing the so-called new economies comes into play in a more explicit way. The new economies, based on principles like smart, sharing, collaborative, circular and green can represent the best possible "partners approaches" to enhance the economic side of the resilience practices. This, being aware that changes are, on the one hand, the set of expected economic goals for a territorial system and, on the other hand, the system itself of the production and consumption models desirable for a sustainable future. The attention to the economic components, in all of these meanings, appears then beneficial and useful, an innovative interpretation key for the evaluation of the resources and forces of a territorial system.

Finally, the renovated urgency to develop and promote innovations in knowledge building processes, capacity building and learning, all to be regarded as crucial key-tools and strategic factors in supporting resilience practices and, in general, the improvement of the resilience of complex systems. The RPO experience made it more clearly appear the urgency of innovation and renovation of capacity building and learning processes of all stakeholders involved in the resilience practices processes. The innovation is needed in order to promote virtuous processes of incremental learning of all stakeholders involved (academic, experts, institutional, operative, citizen...). Consolidated methods have to be integrated with innovative ones, able to engage different stakeholders, working in real context and with local communities, in an active and pro-active role. The resilience practices need to be based on the constant and incremental learning process of all involved actors and on processes of knowledge coproduction, involving multiple sectors and sources, preparing scientific, expert and local communities to understand the dynamic phenomena and to cope and adapt with uncertainty, activating complex strategies also based on psychological and social components.

Under such a perspective, the RPO "becomes" an innovative instrument itself, able to enhance the resilience practices and culture improvement offering a common "place" for developing many possible activities, from research and reframing to assessment and evaluation methodologies up to the promotion of practices through a program of meetings and the RPFs. Actually, an innovative approach to research characterised the RPO and the RPF process, demonstrating the value of the innovative incremental, trans/multi-disciplinary and co-productive methods applied in developing all the RPO activities. Among these, in particular, the definition of comparative and interpretative framework based and capitalising the expert and academic knowledge and the co-production of knowledge and capacity building based on exchange and contamination methods (phenomena and dynamic identification and evaluation). In these terms the RPF activated adaptive processes of incremental learning/capacity building/knowledge building characterized by mutual feedbacks between "the experts and the academics" knowledge and practices, an alliance where the advancement of research based on practices produce differentiated outputs, able to enrich resilience practices initiatives and processes on the ground.

The future of resilience or better, the future resilience of territories and communities will rely a lot on capacity building and cultural based action. There seem to exist interesting potentials and cross effects in better integrating and enhancing the concept and goals of territorial resilience as one of the qualities to be achieved in the renewals beyond the urban areas, promoting innovative models and processes for the regeneration and redevelopment of territorial spaces to be returned to, sustainable, community uses 


\section{Acknowledgments}

This essay was possible thanks to the work and results obtained by the RPO working group. We are grateful to Marcello Magoni, Rachele Radaelli, Stefano Cozzolino e Catherine Dezio for their contribution to the functioning of the Observatory and the active participation to all the activities.

\section{References and Notes}

Borraz, O. \& Le Galès, P. 2010. Urban Governance in Europe: The Government of What?. Pôle Sud, 32,(1), 137-151. https://www.cairn.info/revue-pole-sud-2010-1.htm-page-137.htm.

Colucci A. 2016. La resilienza dei sistemi socio-ecologici, in Resilienza tra Territorio e comunità. Approcci, strategie, temi e casi. Edited by Colucci, A., Cottino, P. Fondazione CARIPLO, Milano.

Colucci A. 2018. Transition Initiatives: Three Exploration Paths in Smart, Resilient and Transition Cities: Emerging Approaches and Tools for A Climate-Sensitive Urban Development edited by Galderisi, A., and Colucci, A. Elsevier.

Dezio C., Colucci A., Magoni M., Pesaro G., Redaelli R. 2016. Observatory of Resilience Practices: Strategies And Perspectives. Paper presented at 1st AMSR Congress and 23rd APDR Congress. Sustainability of Territories in the Context of Global Changes. 30-31 May 2016. Marrakech. pp. 226231. ISBN: 978-989-8780-04-1

Duit A., Galaz V., Eckerberg K., Ebbesson, J. .2010. Governance, complexity, and resilience. Global Environmental Change: 20(3), 363-422. DOI 10.1016/j.gloenvcha.2010.04.006

Dingwerth, K., \& Pattberg, P. 2006. Global governance as a perspective on world politics. Global governance: a review of multilateralism and international organizations, 12(2), 185-203.

Frantzeskaki, N., Kabisch, N., 2016, Advancing urban environmental governance: Understanding theories, practices and processes shaping urban sustainability and resilience. Environmental Science \& Policy: 62 (2016) 90-98. DOI: 10.1016/j.envsci.2016.05.008

Galderisi A., Colucci A. 2018. Future Perspectives: Key Principles for a Climate Sensitive Urban Development. in Smart, Resilient and Transition Cities: Emerging Approaches and Tools for A Climate-Sensitive Urban Development edited by Galderisi, A., and Colucci, A. Elsevier.

Geels, F. W. 2002. Technological transitions as evolutionary reconfiguration processes: a multi-level perspective and a case-study. Research policy: 31(8), 1257-1274. DOI https://doi.org/10.1016/S00487333(02)00062-8.

Kemp, R., Rotmans, J., 2009. Transitioning policy: co-production of a new strategic framework for energy innovation policy in the Netherlands. Policy Sci. 42, 303-322. DOI

Gunderson, L., Holling C.S, Lance, H. 2002. Resilience and Adaptive Cycles, in Panarchy: understanding transformations in human and natural systems edited by Gunderson, L., Holling C.S., (Eds.). Island Press, Washington D.C.

Holling C. S., 1973. Resilience and stability of ecological systems. Annual Review of Ecology and Systematics:, 4(1), 1-23

Loorbach, D. 2010. Transition management for sustainable development: a prescriptive, complexity based governance framework. Governance: 23(1), 161-183. DOI 10.1111/j.14680491.2009.01471.x. 
Olsson, P., Gunderson, L., Carpenter, S., Ryan, P., Lebel, L., Folke, C., \& Holling, C. 2006. Shooting the Rapids: Navigating Transitions to Adaptive Governance of Social-Ecological Systems. Ecology and Society, 11(1). Retrieved from http://www.jstor.org/stable/26267806

Ostrom, E., 1990. Governing the Commons: The Evolution of Institutions for Collective Action. Cambridge University Press, Cambridge.

Ostrom, E. 2005. Understanding institutional diversity. Princeton University Press, Princeton, New Jersey, USA.

Pesaro, G., (2015). Economie della resilienza per lo sviluppo dei sistemi locali, in Resilienza tra Territorio e comunità. Approcci, strategie, temi e casi. Edited by Colucci A. Cottino P. Fondazione CARIPLO, Milano.

Rotmans, J., Kemp, R., \& Van Asselt, M. 2001. More evolution than revolution: transition management in public policy. Foresight: 3(1), 15-31. DOI 0.1108/14636680110803003.

Sellberg M.M., Ryan P., Borgström S.T., Norström A.V., Peterson G.D.. 2018. From resilience thinking to Resilience Planning: Lessons from practice. Journal of Environmental Management. 217, 906-918. DOI 10.1016/j.jenvman.2018.04.012

Voorberg, W. H., Bekkers V. J. J. M., Tummers L. G. 2014. A Systematic Review of Co-Creation and Co-Production: Embarking on the social innovation journey, Public Management Review: 17, n. 9 (21 ottobre 2015): 1333-57. DOI 10.1080/14719037.2014.930505

Voss, J.-P., Bauknecht, D. (Eds.), 2006. Reflexive Governance for Sustainable Development. Edward Elgar Publishing, Cheltenham.

\section{Note}

The paper is based on the paper presented by Angela Colucci and Giulia Pesaro "Rethinking Resilience Practices: lessons learnt from the Italian. Resilience Practices Observatory and development paths", ERSA Congress 2018 Innovative inclusive and liveable Regions and the Chapter 34 "Future Perspectives: Key Principles for a Climate Sensitive Urban Development” by Galderisi A., Colucci A. in Smart, Resilient and Transition Cities: Emerging Approaches and Tools for A Climate-Sensitive Urban Development edited by Galderisi, A., and Colucci, A. Elsevier (2018).

(C) 2018 by the authors; licensee MDPI and IFoU, This article is an open access article distributed under the terms and conditions of the Creative Commons Attribution license. 